\title{
Management of Adverse Effects of Second-generation Antipsychotics in Youth
}

Marie Raffin, $M D^{1}$

Marianna Gianitelli, $M D^{1}$

Angèle Consoli, MD, $P h D^{1}$

Olivier Bonnot, $M D, P h D^{2}$

Marie-Line Menard, $M D^{3}$

Florence Askenazy, MD, PhD ${ }^{3}$

Claudine Laurent, $M D, P h D^{1,4}$

David Cohen, MD, PhD ${ }^{*}, 5$

\author{
Address \\ ${ }^{*}, 1$ Department of Child and Adolescent Psychiatry, Hôpital Pitié-Salpêtrière, \\ AP-HP, 47-83, boulevard de l'Hôpital, 75013 Paris, France \\ Email: david.cohen@psl.aphp.fr \\ ${ }^{2}$ Department of Child and Adolescent Psychiatry, Hôpital Universitaire de \\ Nantes, allée de l'île Gloriette, 44093 Nantes, France \\ ${ }^{3}$ Service Universitaire de Psychiatrie de l'Enfant et de l'Adolescent, Hôpitaux \\ pédiatriques de Nice CHU-LENVAL, 57 avenue de la Californie, 06200 Nice, \\ France \\ ${ }^{4}$ CRICM-CNRS, Institut du Cerveau et de la Moelle, Hôpital Pitié-Salpêtrière, \\ AP-HP, 47-83 boulevard de l'Hôpital, 75013 Paris, France \\ ${ }^{5}$ CNRS UMR 7222, Institut des Systèmes Intelligents et Robotiques, Université \\ Pierre et Marie Curie, 1 place Jussieu, 75005 Paris, France
}

Published online: 9 January 2014

(C) Springer International Publishing AG 2014

Keywords Second-generation antipsychotics · Childhood · Adolescence · Youth · Adverse effects

\section{Opinion statement}

Second-generation antipsychotics (SGAs) have been proven effective in treating several psychiatric conditions in children and adolescents. These atypical antipsychotic medications are being used with increasing frequency in Europe, the U.S., and Canada. We aim to expose shortterm and long-term adverse effects (AEs) of SGAs in youth populations and to provide management recommendations for major adverse effects. These proposals are based on (1) an indepth literature review of both short- and long-term studies on the use of SGAs in youth; (2) our own clinical experience in managing such treatment in this population; and (3) the work of the Canadian Alliance for Monitoring Effectiveness and Safety of Antipsychotics in Children (CAMESA). AEs are frequent in youth treated with SGAs, and include primarily weight gain, metabolic and hormonal changes, somnolence, extrapyramidal syndrome, and QT modifica- 
tions. However, frequency and type of AE vary according to compound, and each compound's AE profile is specific. Acknowledgment of these distinct profiles should aid clinicians in making treatment decisions. After an SGA is prescribed, routine monitoring of AEs is recommended, and should an AE occur, clinical management recommendations should be followed. To date, there are no clinically validated monitoring recommendations.

\section{Introduction}

Atypical or second-generation antipsychotic medications (SGAs) have been proven effective for treating several conditions in children and adolescents. As of March 2010, aripiprazole, olanzapine, quetiapine, and risperidone have been approved by the FDA as medications for bipolar mania in children and adolescents (age 1017 years; except olanzapine, age 13-17 years) and for adolescent schizophrenia (age 13-17 years). In addition, aripiprazole and risperidone are approved for behavioral disturbances (irritability and aggression) associated with autism and/or intellectual disabilities in children and adolescents (age 6-17 years). SGAs were developed to lower the risk of extrapyramidal syndrome (EPS) [1]. Six SGAs are now commonly prescribed to children and adolescents in both the U.S. [2] and Europe [3]. The risk of adverse effects (weight gain, somnolence, and EPS) with olanzapine, however, has been reported to be significantly higher in young patients compared to adults $[4 \bullet]$. Emerging findings indicate that children and adolescents are more vulnerable to weight gain, cardiometabolic effects (increased glucose, triglyceride, and cholesterol levels), and hyperprolactinemia $[5,6]$. This raises concerns about the use of SGAs in children [7]. In the U.S., the number of children treated with SGAs increased $22 \%$ from 2004 to 2008 , with an average of 250,000 prescriptions per year for children under 6 years of age and numerous prescriptions for non-psychotic disorders and off-label indications [8]. In the 50 U.S. states and the District of Columbia, antipsychotic use increased $62 \%$ from 2002 to 2007, reaching a total of 354,000 child and adolescent psychiatric patients by 2007 , most of them presenting bipolar disorders, schizo- phrenia, and autism, comorbid with ADHD in $50 \%$ of the cases [9]. Similarly, in France, SGAs are prescribed primarily for bipolar disorders, schizophrenia, and autism. In a population of 652 young patients receiving psychotropic medication, 154 were treated with a SGA as monotherapy and 237 as a co-prescription [10]. In light of the controversy regarding the use of selective serotonin reuptake inhibitors (SSRIs) in children [11], the 2003 and 2007 Pediatric Research Equity Acts (PREA) and the 2002 Best Pharmaceuticals for Children Act (BPCA) provided incentives for increased numbers of large double-blind placebo-controlled studies on SGAs and other medications in children.

The present review aims to clarify the frequency, type, and management of adverse effects (AEs) of SGAs in youth. First, we will discuss the major AEs found in both short- and long-term studies on the use of SGAs in youth. This is based on an in-depth literature review of a Bayesian meta-analysis based on short-term studies [12•]; a review of long-term studies in SGAs [13-28]; and our own clinical experience in managing such treatment in youth. Second, we will present the major AEs by compound. Third, we will summarize the practical recommendations for the prescription and monitoring of SGAs as put forth by the CAMESA guideline group, as well as discuss settings when switching from one compound to another is indicated. Details of these recommendations are available online at www.camesaguideline.org. [29•, 30•]. Finally, we will discuss clinical and research implications and discuss the design of an ongoing prospective pharmacovigilance study aimed at systematically assessing the secondary effects of SGAs among children and adolescents [31].

\section{Adverse effects of second-generation antipsychotics in youth}

For the purpose of a Bayesian meta-analysis on adverse effects in SGAs [12•], we conducted an in-depth review of the literature. Short-term studies, which 
are summarized in Table 1, comprise 41 case-control studies, 3-12 weeks in length, involving SGA use in children and adolescents with schizophrenia, bipolar disorder, behavioral impairments associated with autism or intellectual disability, Tourette syndrome, and conduct disorder. Most of these studies were supported by industry funding. Long-term AE studies are summarized in Table 2. They include 14 studies with durations ranging from 16 to 64 weeks. Ten of the 14 studies assessed risperidone, and 9 studies were supported by industry funding. Of note, in our review of the Treatment of Early-Onset Schizophrenia Study (TEOSS) assessing long-term safety and effectiveness of olanzapine, risperidone, or molindone among 54 children and adolescents with early-onset schizophrenia, we considered only the olanzapine and risperidone arms, as molindone is not an SGA. [26, 32]. We did not find sufficient data on asenapine and will not discuss any results with this compound. In total, our review comprises the results of 55 studies.

With regard to results from the short-term studies, all compounds but ziprasidone were significantly associated with weight gain compared with placebo/untreated patients. Olanzapine and clozapine demonstrated the highest percentage of patients who experienced meaningful weight gain, a greater increase in body mass index (BMI) and weight as expressed in $\mathrm{kg}$. Aripiprazole and ziprasidone appeared to have less effect on weight gain, although additional studies are needed on ziprasidone, as the number of patients for this compound was low. Risperidone and quetiapine appear to have an intermediate profile [12•].

Long-term studies confirm the occurrence of weight gain. All 10 studies assessing risperidone reported weight gain in the exposed group $(n=358)$. When comparing different SGAs, weight gain was significantly higher for olanzapine compared to risperidone, clozapine, or quetiapine [14, 21, 22]. One study on quetiapine $(n=10)$ reported no significant weight gain or increase in BMI after 64 weeks of treatment [24], while another study reported only moderate weight gain ( $n=24$, duration 25 weeks) [14].

Such short-term differences are nuanced by the results of the TEOSS study assessing long-term safety and effectiveness of olanzapine, risperidone, or molindone among 54 children and adolescents with early-onset schizophrenia. In the first part of the study, weight gain was significantly higher in patients treated with olanzapine, but in the extension trial, no significant differences in weight gain emerged among the various compounds during maintenance treatment [26,32].

Risperidone and olanzapine significantly increased glucose levels compared to placebo. Such differences were not statistically significant for aripiprazole, quetiapine, and ziprasidone. Quetiapine and olanzapine significantly increased cholesterol rates compared to placebo, while the mean increase for aripiprazole, risperidone, and ziprasidone was not significant. Olanzapine and quetiapine significantly increased triglyceride $(\mathrm{mg} / \mathrm{dl})$ levels compared to placebo, but the effect was not significant with risperidone, aripiprazole, and ziprasidone. 


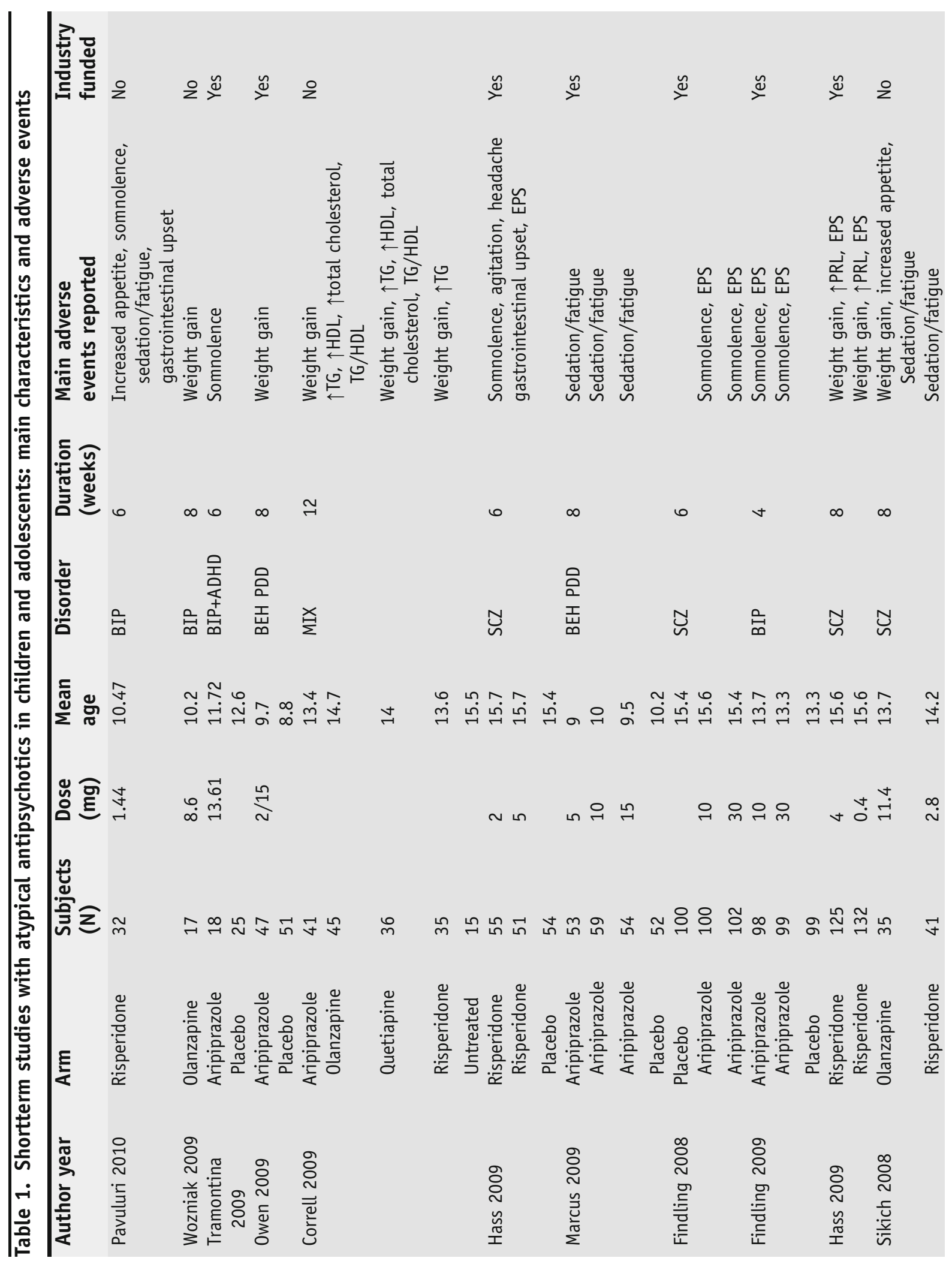




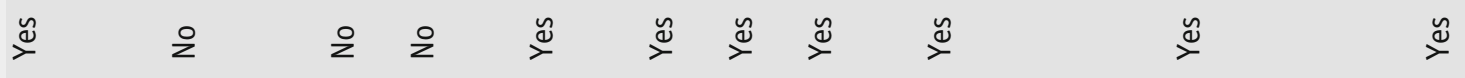

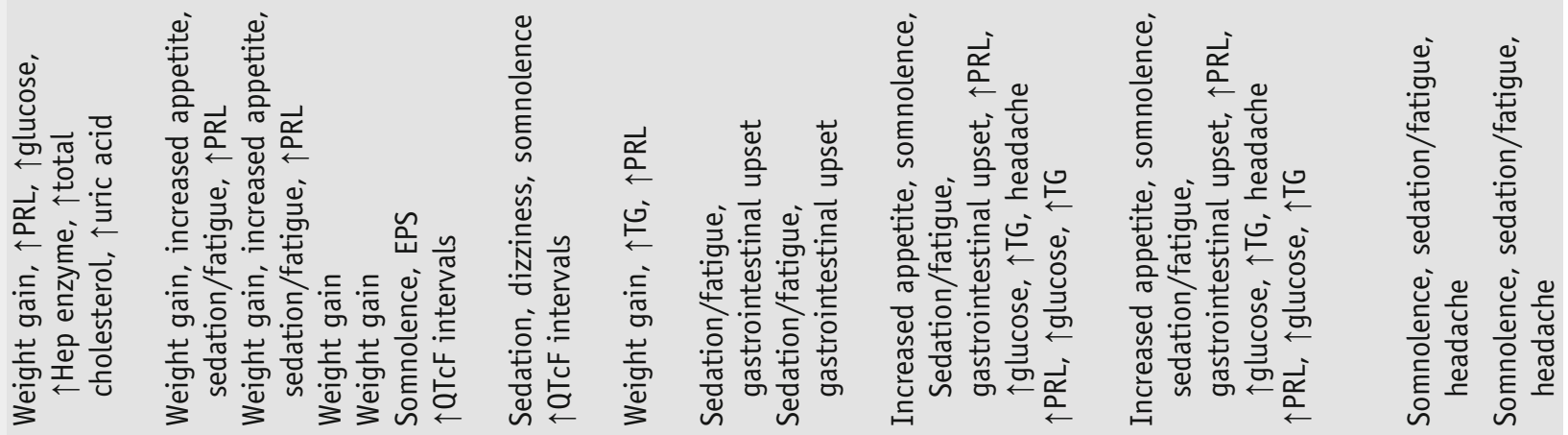

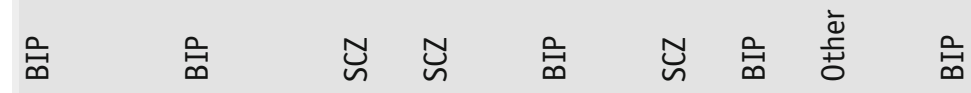

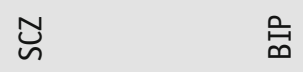

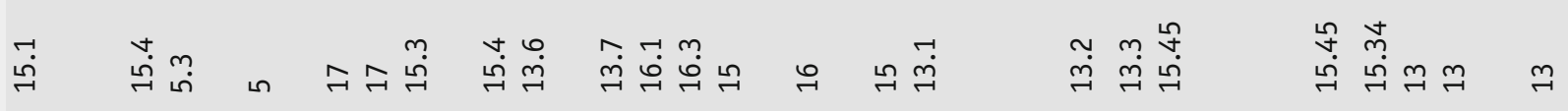

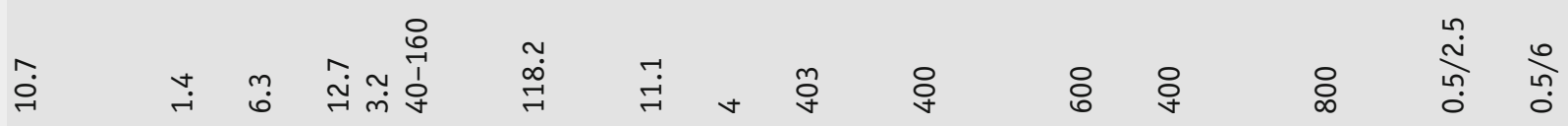

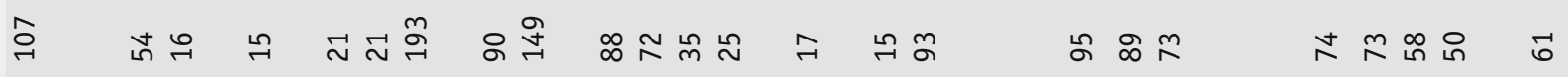

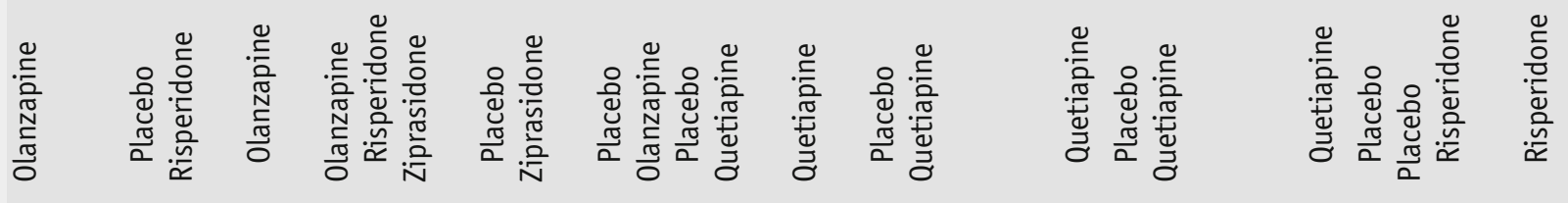

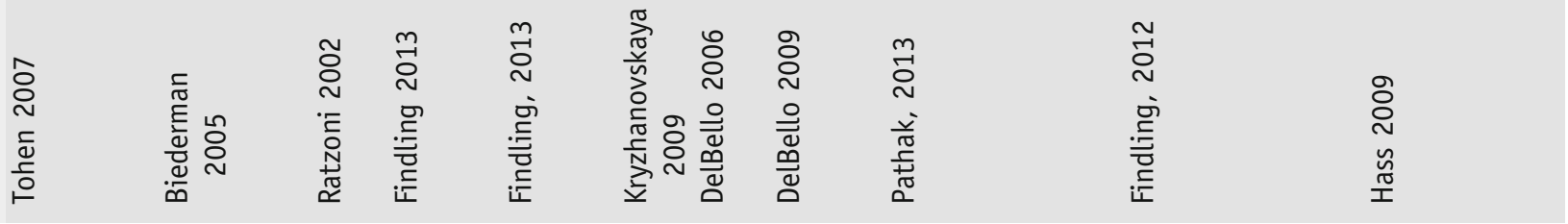




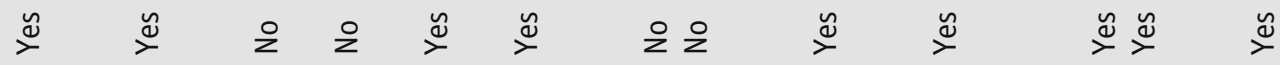

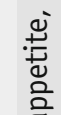

\section{芯芯芯芯 岕}

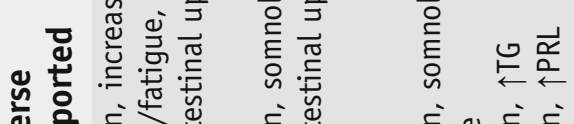

究

离产

蒙莺

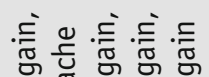

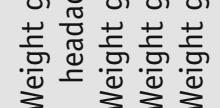
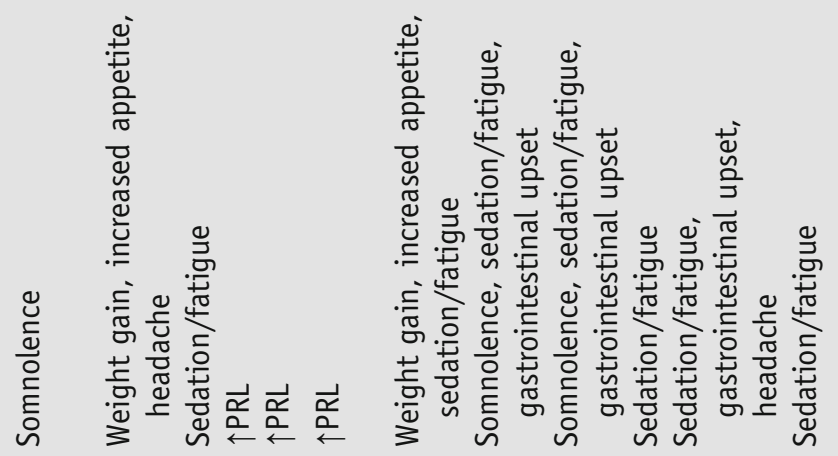

喜

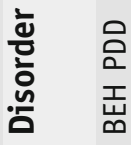

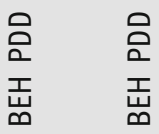

$\simeq 0$

๑

오 군

$\infty \vee$

6

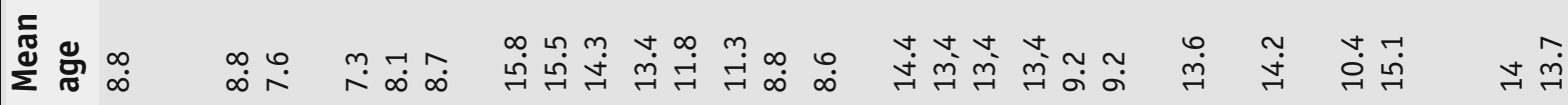

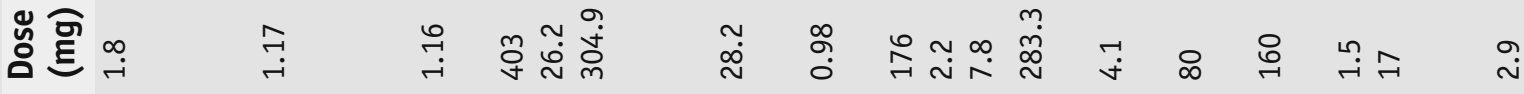

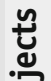

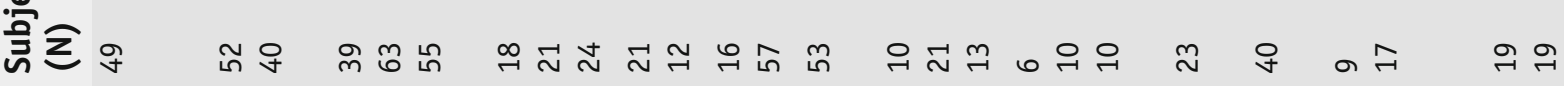

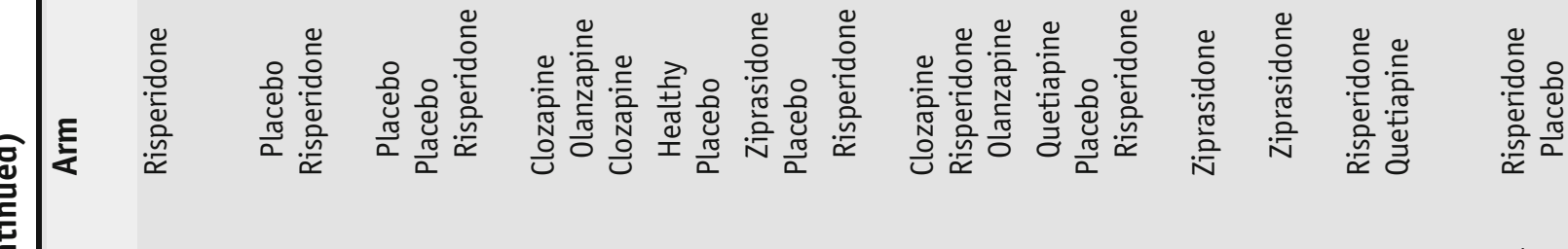

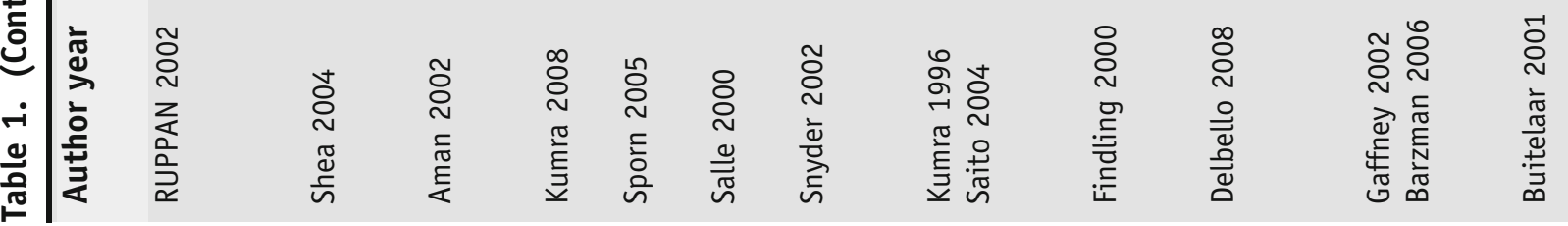




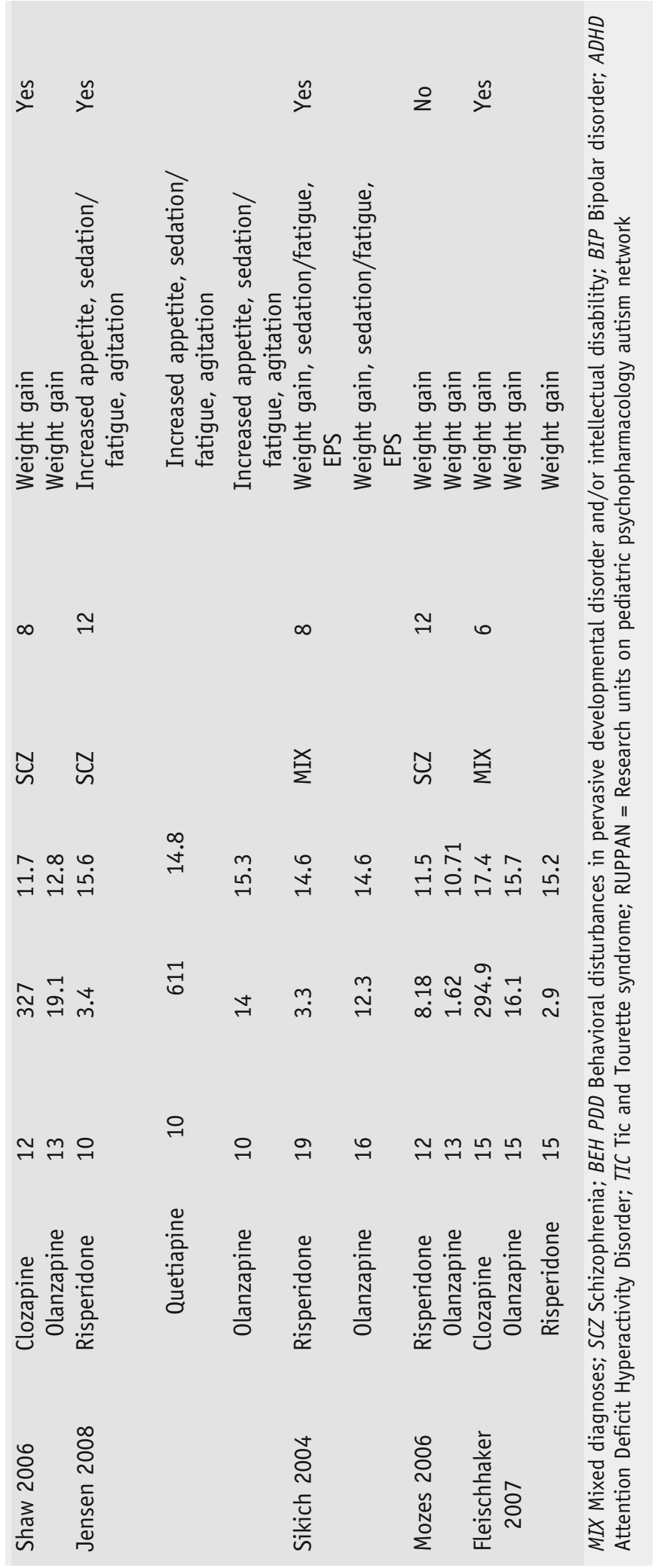




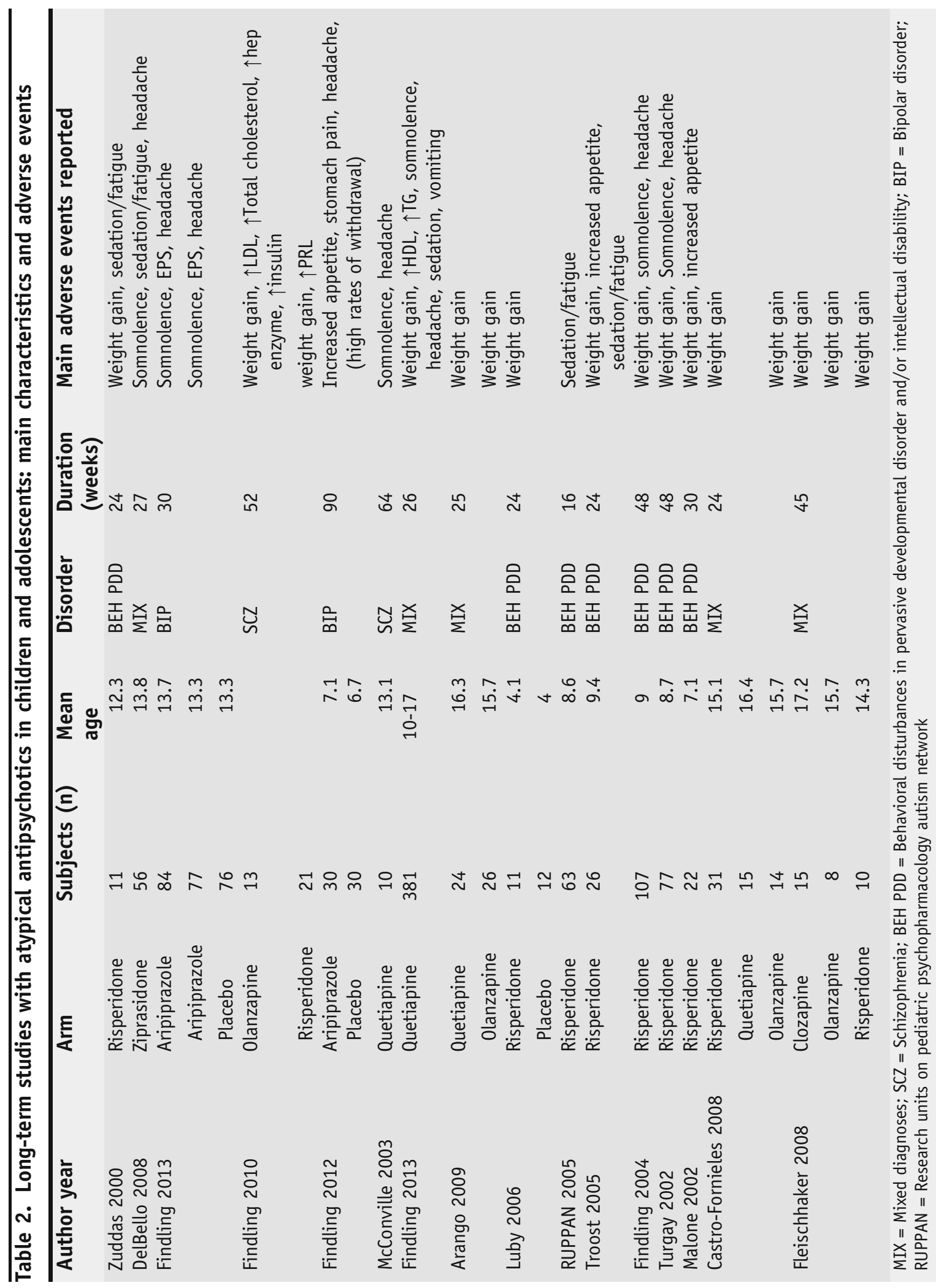


Very few long-term studies reported metabolic changes. One study confirmed the effects of quetiapine and olanzapine on lipid profiles. These two compounds increased total cholesterol rate, and quetiapine also increased HDL cholesterol [14]. With regard to weight change, as mentioned above, no significant differences emerged among the compounds in most of these parameters during maintenance treatment of the TEOSS study [26]. Of note, data are insufficient to conclude any metabolic effect of clozapine. Bobo et al. recently demonstrated that young users of antipsychotics had are at threefold increased risk for type II diabetes. The risk increased significantly with increasing cumulative dose and for use restricted to SGAs or to risperidone [33].

\section{Prolactin (PRL) changes}

Variations in prolactin levels were poorly reported across studies, with the exception of aripiprazole, for which four studies reported a decrease in prolactin. Risperidone, olanzapine, and ziprasidone significantly increased prolactin levels compared to placebo, while the difference reported for quetiapine was not significant. Data on clozapine are insufficient to reach a conclusion (see Table 1).

One long-term study confirmed that aripiprazole decreases PRL $(n=161$, duration 30 weeks) [18]. Three studies assessed PRL changes with risperidone, reporting largely a transitory PRL increase with no clinical impact. [13, $16,19]$. The TEOSS study reported statistical differences in PRL levels among olanzapine, risperidone, and molindone, although this study reported an average decrease rather than increase from baseline for risperidone. Despite this decrease, however, patients receiving risperidone maintained higher PRL levels than patients in other treatment groups. Interpretation of this study is complicated by the fact that patients were not naïve at inclusion [26, 32].

Effects on other hormones have been poorly investigated. Quetiapine appeared to decrease levels of thyroid hormone T4 in one study [14]. Another study on quetiapine also reported a small and intermittent decrease in free thyroxine levels but no change in mean thyroid-stimulating hormone levels [24].

Somnolence/sedation

As was the case for long-term studies, most short-terms studies reported a significantly increased risk for somnolence/sedation for all compounds compared to placebo [12•, 13, 17-20, 23-25].

\section{Extrapyramidal syndrome (EPS)}

With the exception of quetiapine and clozapine, all SGAs significantly increased the risk of EPS compared to placebo in the short-term studies. Although there was no report of EPS (including akathisia) in clozapine studies, it was unclear whether incidence of EPS was systematically assessed. Notably, the odds ratios (OR) of EPS for ziprasidone reached the level of haloperidol, challenging the view that it belongs in the group of SGAs to treat youth [12 $\bullet$.

With regard to the results of long-terms studies, rigidity was more frequent in patients with olanzapine than quetiapine [14], and hypokinesia was more frequent with risperidone than olanzapine and clozapine. In a 6month naturalistic study, risperidone increased the risk of EPS compared to olanzapine [21]. Regarding acute dyskinesia, five dystonia were reported in 
patients treated with risperidone, two of which were withdrawal dyskinesia $[18,20,25]$.

Among the long-term studies, no tardive dyskinesia was described, but longer monitored studies are needed to assess tardive dyskinesia/dystonia. Data from the single cases that have been reported [34], seem to indicate that (1) tardive dyskinesia/dystonia is a rare AE of SGAs; (2) body dystonia are more frequent than extremities/oral dyskinesia in children and adolescents; and (3) tardive dyskinesia/dystonia may be more frequent in young people compared to adults (this was demonstrated for olanzapine in a pharmacovigilance study $[4 \bullet])$.

A number of medications commonly used in pediatric psychopharmacology can prolong the QT interval on the electrocardiogram, which in turn can predispose to torsades de pointes, a sometimes deadly arrhythmia [35]. While most reports of prolonged QT interval have involved adult patients, this adverse effect can also occur in children. Reporting on this AE is limited. Some studies did not assess ECG modifications [36-41], and so a meta-analytic approach was not possible [12•]. In short-term studies, no effect on ECG was reported in 13 studies with risperidone [32, 42-53]. One study reported prolonged QT interval in one patient with risperidone [54]. Four studies reported no changes in ECG among groups with olanzapine [48, 49, $51,55,56]$. One study reported that the rate-corrected QT (QTc) intervals measured by ECG increased significantly $(11.2 \mathrm{~ms})$ in the olanzapine group [32]. Five studies reported no changes in ECG parameters with aripiprazole [57-61]. Few studies assessed cardiac effects of ziprasidone among young patients. Of those that did, two studies found no clinical cardiac effects $(n=12)$ and no ECG modifications $(n=28)$, whereas one study $(n=13)$ found a 19-ms prolongation in the one child for whom both baseline and followup ECG data were available [35]. Of note, the large A1281132 study investigating the efficacy of ziprasidone in adolescent bipolar disorder reported a significant increase in QT intervals (Table 1). Finally, regarding quetiapine, no ECG modifications were observed in five studies with quetiapine [27, 48, $62,63]$, and no data were available for clozapine.

ECG was not systematically reported as a monitoring parameter in the long-term studies. One study reported that among 10 patients with quetiapine, two asymptomatic patients had mildly prolonged QTc intervals [24]. Five studies on risperidone (total 228 patients) reported no clinically relevant mean change in ECG measures [18-20, 25]. Among 56 patients with ziprasidone, the authors reported one case of prolonged QTc interval (QTc> $450 \mathrm{~ms})$ during a 24 -week period [23]. One study on olanzapine $(n=26)$ and quetiapine $(n=24)$ reported no changes in ECG during a 25 -week period.

\section{Summary of AEs by compound}

A significant frequency of AE was found for all six compounds investigated here (aripiprazole, clozapine, olanzapine, quetiapine, risperidone, and ziprasidone), but the profile of each compound was quite unique. Table 3 summarizes semi-quantitatively the frequency of AE per compound. We 


\begin{tabular}{|c|c|c|c|c|c|c|}
\hline & Aripiprazole & Clozapine & Olanzapine & Quetiapine & Risperidone & Ziprasidone \\
\hline$\pi$ Weight & + & ++++ & ++++ & +++ & ++ & $+/-$ \\
\hline Alucose & $+/-$ & $?$ & + & $+/-$ & ++ & 0 \\
\hline$\pi$ Cholesterol & 0 & ? & +++ & ++++ & 0 & 0 \\
\hline ^Triglycerides & 0 & +++ & ++++ & ++++ & $+/-$ & 0 \\
\hline Hyperprolactinemia & 0 & $?$ & +++ & $+/-$ & ++++ & ++ \\
\hline Sedation & ++ & ++++ & ++ & + & ++ & ++ \\
\hline $\begin{array}{l}\text { Extrapyramidal } \\
\text { syndrome }\end{array}$ & + & $0 ?$ & ++ & $+/-$ & + & ++++ \\
\hline $\begin{array}{l}\text { Change in } \\
\text { ECG parameters }\end{array}$ & $+/-$ & + & $+/-$ & $++?$ & + & +++ \\
\hline
\end{tabular}

briefly review them in alphabetical order, adding comments regarding switching from one compound to another when needed.

Aripiprazole has the most advantageous profile regarding weight gain and metabolic parameters in adults. In children and adolescents, however, there is significant moderate weight gain. The clinical significance of the decrease in PRL is unknown. The long half-life (3 days) of aripiprazole and its partial agonist profile warrant careful monitoring if a switch is made to this compound due to the high rebound-effect risk (see below), and therefore a "plateau" switch is required [64•]. This profile explains the particular high frequency of dopaminergic rebound if the first SGA is stopped quickly when aripiprazole is introduced. Dopaminergic rebound is characterized by psychotic symptoms, aggressiveness, agitation, manic symptoms, and akathisia [65]. Regarding ECG parameters, clinically significant QTc interval prolongation was not noted in any of several studies of adults [35], and short-term studies conducted in youths also reported no ECG changes (Table 1).

However, further studies are needed to evaluate possible rare or long-term ECG effects [35].

The most significant and specific AE of clozapine is the risk of agranulocytosis. Although the incidence of agranulocytosis is rare, clinicians should carefully monitor white blood cell count, at first weekly as treatment is initiated and then monthly. Additional data are needed in order to determine the metabolic, PRL level, and neurological secondary effect profiles of clozapine. Similarly to olanzapine, weight gain with clozapine can be particularly significant in young patients, although one long-term study found less significant weight gain with clozapine compared to olanzapine [22]. Sedation is also an issue in younger patients. When a patient requires a switch from a high-affinity D2 receptor (e.g., risperidone) to clozapine (which presents a lower D2 receptor affinity value), a dopaminergic rebound can 
occur with supersensitivity to psychosis, akathisia, agitation, or aggressiveness. These symptoms must be interpreted carefully, as they may not reflect lack of efficacy of clozapine [65]. Tachycardia has been reported in child and adolescents, [66] but more studies are needed to evaluate ECG effects [35].

Olanzapine is associated with the most significant rate of weight gain. This compound was shown to significantly increase glucose, cholesterol and triglyceride, and prolactin levels. Olanzapine also increases the risk of somnolence/sedation and EPS. It appears to be the only compound that significantly increased all of the parameters in our meta-analysis. Two longterm studies compared olanzapine to risperidone, quetiapine, and clozapine, in whicholanzapine was associated with significantly more weight gain than other treatments [14, 21, 22]. The TEOSS study, however, reported no significant differences in weight gain during maintenance treatment [26]. With regard to the effect on QTc intervals, an in-depth review by Blair et al. reported that evidence for QTc interval prolongation in olanzapine was equivocal, at best, and that olanzapine was safer than other antipsychotics in this regard, at least at relatively low doses [35]. In the U.S., a large pharmacovigilance study analyzed more than 4 million olanzapine prescriptions, including 24,000 children, 234,000 adolescents. and 4,073,000 adults. Sedation, weight gain, liver function, and tardive dyskinesia were overrepresented AEs among children and adolescents vs. adults. Complaints of increased appetite were 24 times higher in children than in adults and 6 times higher in adolescents than in adults. Complaints of weight gain were 4.3 times higher for children and 3.2 times higher for adolescents than for adults. Sedation complaints were 4.5 times higher in children and 1.9 times higher in adolescents than in adults. Complaints of tardive dyskinesia were 4.1 times higher in children than in adults, and complaints in adolescents were similar to those in adults. This result must be interpreted with caution, as this adverse effect is rare and requires longer periods of treatment to emerge. Liver function test abnormalities were 3.4 times higher in children than in adults, 1.9 times higher in adolescents than in adults, and 1.8 times higher in children than in adolescents. One explanation for this may be that pediatric clinicians monitored liver function test results more frequently than clinicians treating adults $[4 \bullet]$.

Quetiapine appears to have an interesting EPS profile in that it is the only compound that does not increase the risk of EPS compared to placebo. With regard to metabolic complications, quetiapine has intermediate profiles, with moderate weight gain, increases in triglyceride and cholesterol blood levels, and no significant differences in glucose and PRL blood levels $[67,68]$. Three long-term studies assessing quetiapine confirmed the moderate effect on weight gain $[14,21,24]$. Two long-term studies reported a decrease in thyroid hormone T4 $[14,24]$. We still do not have sufficient data to come to a conclusion on the cardiologic effects of quetiapine, as only one long-term study reported an intermittent, asymptomatic, mild prolongation of QTC interval [24]. In terms of switching, the same dopaminergic rebound de- 
scribed with the introduction of clozapine can be observed with quetiapine $[64 \bullet, 65]$.

\section{Risperidone}

Risperidone has an intermediate profile with regard to weight gain, with moderate weight gain experienced. It increases blood glucose levels and PRL, but short-term elevation of triglyceride and cholesterol levels is not statistically significant. AE is similar to the other compounds with regard to sedation and EPS. Regarding its cardiac AE profile, QTc interval prolongation is a possibility in risperidone-treated patients of all ages, although it appears to be a rare event [35]. Long-term studies have confirmed results of short-term studies on weight gain and somnolence. According to some authors, the fact that the increase in PRL with risperidone appears to be more frequent in girls than boys may be of significant concern, as an increase in PRL during adolescence affects the number of osteoblasts and could be associated with increased risk of osteoporosis later in life [69].

Ziprasidone has the most significant rate of EPS, with an OR of 20 compared to placebo. Given the low frequency of weight and metabolic AEs, this particular profile seems closer to typical antipsychotics than to SGAs in young patients $[12 \bullet, 70]$. Regarding ECG parameters, ziprasidone is an SGA that has been under close scrutiny before and since its approval in 2001 due to its propensity to prolong the QTc interval in adults beyond that of all other SGAs prescribed to young patients. Preliminary studies conducted by the manufacturer found that ziprasidone prolonged the QTc interval 9-14 ms longer than four other drugs (risperidone, olanzapine, haloperidol, and quetiapine) and that few cases of sudden death had occurred in patients taking therapeutic doses [35]. Given the limited data on ECG changes in children and adolescents with ziprasidone, more studies are needed to clarify this risk. However, preliminary findings by Blair et al. [71] and from the two large randomized controlled industry studies, (Table 1) suggest that close electrocardiographic monitoring is warranted when prescribing ziprasidone to children [70, 72].

\section{Monitoring adverse effects of second-generation antipsychotics}

Screening schedule and recommendation

We previously concluded that AEs are common among youth treated by SGAs. As AEs are not systematically reported in studies, monitoring of side effects would improve long-term health outcomes. We will focus only on the most common AEs. The CAMESA guideline group proposed a screening schedule to systematically assess adverse effects of SGAs [30 0 .

At baseline, months 1, 2, 3, 6, 9, and annually thereafter, clinicians should measure each patient's weight, height, BMI, waist circumference, and blood pressure, and proceed to a neurological examination. Regarding laboratory evaluations, fasting plasma glucose, fasting insulin, and fasting 
lipid profile should be measured at baseline, 3 and 6 months, and annually thereafter. Thyroid-stimulating hormone (only for quetiapine) and liver function should be measured at baseline, 6 months, and annually, and prolactin should be measured at baseline, 3 months, and annually thereafter. Electrocardiogram (ECG) should be performed at baseline and repeated at 6 months and annually. In addition, ECG should be repeated in the event of dose change, addition of new drug, or attainment of steady state [35]. If the measure is normal, the authors recommend repeating measurement at next scheduled screen.

\section{How to manage adverse effects when they occur}

The CAMESA guideline group proposed strategies in the event of occurrence of each adverse effect. We briefly summarize these strategies and comment on possible alternatives.

\section{Weight gain and/or other weight parameters}

To minimize weight gain, patient should first receive counselling (nutrition, lifestyle, and exercise). After this, four options must be considered: discontinuation of medication, reduction of dose, switch to other SGA, and/or modified additional treatment (stopped, changed, and reduced). In this case, the consideration of metformin is an option to be discussed with an expert. This last proposal should be taken with caution, given the other psychotropic effects of such compound.

\section{Blood pressure and electrocardiogram (ECG) changes}

In the case of prehypertension, recheck blood pressure (BP) in 6 months, and consider specialist consultation if $\mathrm{BP}$ is still elevated at that time. In the case of stage 1 hypertension, recheck BP in 1-2 weeks, or sooner in the case of clinical symptoms. If BP is persistently elevated on two subsequent occasions, consider specialist consultation within 1 month. In the case of stage 2 hypertension, consult a specialist within 1 week, or immediately if symptomatic. In the case of severe hypertension, proceed to an immediate assessment by a specialist for investigation and management. Patients with malignant hypertension should be referred to the nearest emergency room. For definitions of hypertension stages, please refer to "Management recommendations for metabolic complications associated with second-generation antipsychotic use in children and youth" [29•]. When changes in ECG parameters occur, refer to a pediatric cardiologist and consider alternate therapy if resting heart rate remains higher than 130 beats/min, PR remains longer than $200 \mathrm{~ms}$, QRS remains longer than $120 \mathrm{~ms}$ (or $25 \%$ change from baseline value), or QTc remains longer than $450 \mathrm{~ms}$ [30•].

\section{Fasting plasma glucose and insulin}

For individuals with FPG value of 5.6-6 mmol/l, consideration should be given to performing an oral glucose tolerance test (OGTT). If fasting insulin level is above the upper limit of normal for the assay being used, consider oral glucose tolerance test and specialist consultation. We also recommend 
considering switching SGA medication. If FPG is impaired (FPG 6.1$6.9 \mathrm{mmol} / \mathrm{l})$, consider oral glucose tolerance test and specialist consultation, with consideration of metformin. In the case of diabetes (FPG $\geq 7 \mathrm{mmol} / \mathrm{l}$ ), consult with specialist for the management of diabetes.

\section{Fasting lipid profile}

In the case of abnormal low-density lipoprotein (LDL) ( $\geq 3.35 \mathrm{mmol} / \mathrm{l})$, nonhigh-density lipoprotein (HDL) cholesterol (total cholesterol minus HDL) $\geq 3.7 \% \mathrm{mmol} / \mathrm{l}$, or abnormal HDL ( $<1.05 \mathrm{mmol} / \mathrm{l})$ or triglyceride (TG) $(\geq 1.5 \mathrm{mmol} / \mathrm{l})$, recommendations are (1) to re-evaluate the use of the antipsychotic medication in order to minimize weight gain, and (2) to consider cognitive/behavioural lifestyle intervention aimed at weight loss. In the case of elevated LDL ( $\geq 4.15 \mathrm{mmol} / \mathrm{l})$ despite aggressive lifestyle, diet, and exercise modification, as described above, for 3-6 months, consultation with a specialist for possible medical therapy is recommended. In the case of TG $\geq 5 \mathrm{mmol} / \mathrm{l}$, consider consultation with a specialist for possible medical therapy.

\section{Liver function}

In the case of abnormal ASAT/ALT levels, consider specialist consultation for further investigation and management to assess drug implication of such increase. In the case of drug-induced ASAT/ALT increase, consider switching SGA.

\section{Thyroid-stimulating hormone (TSH)}

TSH is required only for quetiapine. In the case of abnormal TSH level, consider assessment of free thyroxine levels and consider specialist consultation for further investigation and management.

\section{Prolactin elevation and related side effects}

In the case of elevated prolactin levels, re-evaluate the use of the antipsychotic medication. Here, a few strategies could be considered: (1) reducing the dose of SGA, as there is some evidence to support that PRL elevation and PRL-related side effects are dose-dependent for risperidone and olanzapine $[73,74]$; (2) switching to a prolactin-sparing agent (clozapine, quetiapine, or aripiprazole); and (3) if SGA switch cannot be made, considering specialist consultation for further investigation and management. In the case of clinical concern and PRL-related side effects, consider specialist consultation for further investigation regarding other causes of hyperprolactinemia and/or amenorrhea.

\section{Extrapyramidal syndrome (EPS)}

In the case of EPS, and when discontinuing medication is not possible, the first option is dose reduction, and the second is to switch to another SGA and/or modify the prescription using additional treatment such as antiparkinson drugs (e.g., tropatepine). With regard to long-term neurological adverse effects, it is important to distinguish between tardive dyskinesia and tardive dystonia (Table 4). Tardive dystonia are a serious issue among 


\section{Table 4. Distinctions between tardive dystonia and tardive dyskinesia}

\author{
Tardive dystonia \\ Young subjects \\ During treatment \\ Male $>$ Female \\ Significant pain \\ Severe disability \\ Rare remission \\ Improved by anticholinergics \\ Response to clozapine \\ From Charfi et al., 2004 [34]
}

\author{
Tardive dyskinesia \\ Elderly \\ During and after treatment \\ Female $>$ Male \\ Unusual pain \\ Mild disability \\ Frequent remission \\ Worsened by anticholinergics \\ No response to clozapine
}

young patients, occurring preferentially in the trunk, characterized by involuntary muscle contractions [34]. When tardive dystonia is generalized, either L-dopa or high doses of anticholinergics may be considered, with benzodiazepine and baclofen potentially added as adjuvant treatment. In case of focal dystonia, botulinum toxin A is the first-line treatment. When an antipsychotic treatment is still required for the patient's condition, switching to another atypical antipsychotic may be helpful for both tardive dystonia and the underlying condition. Clozapine appears to be the first-line therapeutic option when a patient needs antipsychotics. Finally, in the context of behavioural manifestations associated with autism, we want to emphasize that severe akathisia is sometimes difficult to distinguish from tardive dyskinesia, and discontinuation of medication with careful observation is required to reconsider SGA needs.

\section{Clinical and research implications}

\section{Comments on current knowledge}

Most of the studies reviewed here are not comprehensive, and most were focused on efficacy rather than adverse effects. Fortunately, the dearth of knowledge with regard to AEs has improved over recent years following the Pediatric Act. With regard to the studies on short-term adverse effects, several limitations should be acknowledged: the variable reporting of secondary effects, the lack of data on clozapine and ziprasidone, the absence of data on asenapine, the limited number of studies independent of industry funding, the limited number of studies comparing active compounds, the absence of randomization in most observational studies, and the lack of data on concomitant medications that appears to be the rule in everyday practice [10]. Although it is the nature of clinical care not to treat patients for extended periods of time if they cannot tolerate a treatment, the major limitation of long-term studies is that most are follow-up studies from industry-funded acute-phase randomized placebocontrolled trials, and thus patients with the most serious adverse effects are excluded before the longer open phase, which causes the secondary-effect profiles to be biased. In addition, large comparative multisite studies such as the Clinical Antipsychotic Trials of Intervention Effectiveness (CATIE) [75], the Cost Utility 
of the Latest Antipsychotic Drugs in Schizophrenia Study (CUtLASS) [76], and the European First Episode Schizophrenia Trial (EUFEST) [77], that have been conducted in adult patients still need to be performed in young patients.

\section{Switching from one SGA to another}

As stated above, in the case of persistent $\mathrm{AE}$, switching antipsychotics must be considered. Receptor affinity profile and half-life of each SGA should be considered before the switch. A dopaminergic rebound effect can be observed when the introduced antipsychotic has a lower affinity for the dopamine D2 receptor than the initial antipsychotic or if it is a partial agonist with a particularly long life, such as aripiprazole. Dopaminergic hyperactivity rebound includes manifestations of dyskinesia, akathisia, and/or exacerbation of psychotic symptoms (or supersensitivity psychosis). A cholinergic or histaminergic rebound can be expected if the new antipsychotic has lesser affinity for these two receptors. Clinically, this manifests as nausea, vomiting, insomnia, diarrhea, agitation, headache, and sweating.

At this point, it is then recommended to proceed to an overlapping or "plateau" switch, which is to progressively introduce the new compound up to therapeutic doses, to maintain the first treatment during this introduction, and then to slowly decrease the treatment being discontinued [65]. The "plateau" switch, which is the best alternative to limit rebound effects, is particularly interesting in four cases: (1) when the first compound has a high histaminergic or cholinergic affinity and the new compound has a low affinity for these two receptors (e.g., changing from risperidone to quetiapine or clozapine); (2) when the switch comes from a short-half-life compound to a long-half-life compound (e.g., changing from quetiapine or risperidone to aripiprazole); (3) when the initial compound has a high dopamine affinity and the new compound has a low affinity for the DA receptor (e.g., changing from risperidone to quetiapine); and (4) when the initial compound has a high dopamine affinity and the new compound is a partial agonist (e.g., changing from risperidone to aripiprazole) [64•].

When a "plateau" switch is not possible (e.g., in the case of agranulocytosis with clozapine), certain adjuvant treatments may be used to limit the rebound effect. Anticholinergics may help to control the cholinergic rebound, and benzodiazepines or sedative treatment may be useful when a high-histaminergic-affinity treatment is discontinued. A short hospitalization may also be useful. In the case of supersensitivity psychosis, benzodiazepines and anticholinergics may be helpful. The aim of all of these strategies is to maintain a sufficient relevant receptor blockade during the switch.

Adverse effects due to a switch are observed at different times: cholinergic rebound and akathisia are observed in the very first days; parkinsonism rebound occurs after one week of discontinuation; dyskinesia due to discontinuation could appear within a month. The reintroduction of the SGAs will ensure that these are rebound symptoms, as they will stop with this reintroduction.

As stated above, there is an urgent need for long-term multi-arm comparative studies of SGAs in child and adolescent patients, investigating both efficacy and adverse effects, as has been done in studies of first psychotic episodes in young adults. [12•, 78]. In children and adolescents, the TEOSS study 


\section{Conclusion}

(comparing molindone, risperidone, and olanzapine in early-onset schizophrenia) tried to achieve these goals, but only $46 \%$ (54/116) of the subjects entered maintenance treatment after the acute phase (molindone, $n=20$; olanzapine, $n=13$; risperidone, $n=21$ ) [26]. The lack of statistical power led to cautious interpretation of the data. There is also the need for detailed pharmacovigilance studies based on a large prescription database. The study on olanzapine offered important information regarding $\mathrm{AE}$ in young patients $[4 \bullet]$, but other compounds have not been investigated in the same way.

The proposals made in the current review, which are based mainly on the monitoring recommendations of the CAMESA guideline group, are in need of empirical validation. This is ongoing within the context of a large prospective naturalistic multicentre study begun in France in 2013 [31]. The ETAPE study (Etude de la Tolérance des AntiPsychotiques chez l'Enfant) aims to monitor SGA AEs among drug-naïve children and adolescents aged 618 years over the period of one year. Clinical evaluation and laboratory testing will follow the CAMESA guideline group schedules, adding scales to monitor severity and vitamin D variation, as this will better document the risk of osteoporosis [69].

Adverse effects occur frequently with SGAs, weight gain and metabolic AEs in particular. We still do not know the long-term consequences ascribed to SGAs for child and adolescent patients. Nevertheless, each compound has a specific profile that could assist clinicians in choosing the SGA according to the individual risk factor of each patient. A systematic monitoring schedule could lead to early detection of $\mathrm{AE}$ for appropriate targeted intervention, which could help to limit the long-term consequences of AEs.

\section{Acknowledgment}

The current study was supported by a grant from the European Union FP7 (PERS), the University Pierre et Marie Curie, and the Assistance Publique - Hôpitaux de Paris. None of these funding organizations had any role in the design or conduct of the study or in the preparation, review, or approval of the manuscript. NB had full access to all of the data in the study and takes responsibility for the integrity of the data and the accuracy of the data analysis.

\section{Compliance with Ethics Guidelines}

\section{Conflict of Interest}

Marie Raffin, Marianna Gianitelli, Marie-Line Menard, Florence Askenazy, Claudine Laurent declare that they have no conflict of interest.

During the past two years, David Cohen reported past consultation for or the receipt of honoraria from BristolMyers Squibb, Otsuka, Shire, Lundbeck and IntegraGen.

Olivier Bonnot reported past consultation for or the receipt of honoraria from Otsuka and Actelion. Angèle

Consoli reported receiving travel support from BMS. 
Human and Animal Rights and Informed Consent

This article does not contain any studies with human or animal subjects performed by any of the authors.

\section{References and Recommended Reading}

Papers of particular interest, published recently, have been highlighted as:

- $\quad$ Of importance

1. Cohen D, Raffin M, Canitano R, Bodeau N, Bonnot $\mathrm{O}$, Périsse $\mathrm{D}$, et al. Risperidone or aripiprazole in children and adolescents with autism and/or intellectual disability: A Bayesian meta-analysis of efficacy and secondary effects. Res Autism Spectr Dis. 2013;7:167-75.

2. Olfson M, Blanco C, Liu L, Moreno C, Laje G. National trends in the outpatient treatment of children and adolescents with antipsychotic drugs. Arch Gen Psychiatry. 2006;63(6):679-85.

3. Acquaviva E, Legleye S, Auleley GR, Deligne J, Carel D, Falissard BB. Psychotropic medication in the French child and adolescent population: prevalence estimation from health insurance data and national self-report survey data. BMC Psychiatry. 2009;9:72.

4. Woods SW, Martin A, Spector SG, McGlashan TH. Effects of development on olanzapine-associated adverse events. J Am Acad Child Adolesc Psychiatry. 2002;41(12):1439-46.

This is a large pharmacovigilance study on more than 4 million olanzapine prescriptions in the USA. Authors showed that the risk of complaints for, weight gain, sedation, dystonia and tardive dyskinesia is 4 to 5 times more frequent among children than adults. The risk for sedation is two times higher among adolescent than adults and regarding weight gain the risk of complaints is tree time more frequent among adolescent than adults.

5. Correll CU, Manu P, Olshanskiy V, Napolitano B, Kane JM, Malhotra AK. Cardiometabolic risk of second-generation antipsychotic medications during first-time use in children and adolescents. JAMA. 2009;302(16):1765-73.

6. Bonnot $\mathrm{O}$, Inaoui $\mathrm{R}$, Lloret $\mathrm{C}$, Cohen D. Surveillance of metabolic syndrome, hyperprolactinemia and cardiac side effects in children and adolescent treated with antipsychotic. Actuality and recommendations. Neuropsychiatr Enf Adolesc. 2010;58:431-8.

7. American Diabetes Association. Consensus development conference on antipsychotic drugs and obesity and diabetes. Diabetes Care. 2004;27(2):596-601.

8. Governale L, Mehta H. Outpatient use of atypical antipsychotic agents in the pediatric population: years 2004-2008 2009 [cited 2010 07/26]; Available from: http://www.fda.gov/downloads/ AdvisoryCommittees/CommitteesMeetingMaterials/ PediatricAdvisoryCommittee/UCM193204.pdf.

9. Matone M, Localio R, Huang YS, dos Reis S, Feudtner C, Rubin D. The relationship between mental health di- agnosis and treatment with second-generation antipsychotics over time: a national study of U.S. Medicaidenrolled children. Health Serv Res. 2012;47((5):183660. doi:10.1111/j1475-6773201201461x.

10. Acquaviva E, Legleye S, Auleley GR, Deligne J, Carel D, Falissard BB. Psychotropic medication in the French child and adolescent population: prevalence estimation from health insurance data and national self-report survey data. BMC Psychiatry. 2009;9:72. doi:10.1186/1471-244X-9-72.

11. Cohen D. Should the use of selective serotonin reuptake inhibitors in child and adolescent depression be banned? Psychother Psychosom. 2007;76(1):5-14.

12. Cohen D, Bonnot O, Bodeau N, Consoli A, Laurent C. Adverse effects of second-generation antipsychotics in children and adolescents: a Bayesian metaanalysis. J Clin Psychopharmacol. 2012;32(3):30916. doi:10.1097/JCP0b013e3182549259.

This meta-analysis provides a critical analysis of tolerability of SGA in children and adolescents.

13. Findling RL, Correll CU, Nyilas M, Forbes RA, McQuade RD, Jin N, et al. Aripiprazole for the treatment of pediatric bipolar I disorder: a 30-week, randomized, placebo-controlled study. Bipolar Disord. 2013;15(2):138-49. doi:10.1111/bdi12042.

14. Arango C, Robles O, Parellada M, Fraguas D, RuizSancho A, Medina O, et al. Olanzapine compared to quetiapine in adolescents with a first psychotic episode. Eur Child Adolesc Psychiatry. 2009;18(7):41828. doi:10.1007/s00787-009-0749-5.

15. Risperidone treatment of autistic disorder: longerterm benefits and blinded discontinuation after 6 months. Am J Psychiatry 2005;162(7):1361-9.

16. Luby J, Mrakotsky C, Stalets MM, Belden A, Heffelfinger A, Williams $M$, et al. Risperidone in preschool children with autistic spectrum disorders: an investigation of safety and efficacy. J Child Adolesc Psychopharmacol. 2006;16(5):575-87.

17. Troost PW, Lahuis BE, Steenhuis MP, Ketelaars CE, Buitelaar JK, van Engeland H, et al. Long-term effects of risperidone in children with autism spectrum disorders: a placebo discontinuation study. J Am Acad Child Adolesc Psychiatry. 2005;44(11):1137-44.

18. Findling RL, Aman MG, Eerdekens M, Derivan A, Lyons B. Long-term, open-label study of risperidone in children with severe disruptive behaviors 
and below-average IQ. Am J Psychiatry. 2004;161(4):677-84.

19. Turgay A, Binder C, Snyder R, Fisman S. Long-term safety and efficacy of risperidone for the treatment of disruptive behavior disorders in children with subaverage IQs. Pediatrics. 2002;110(3):e34.

20. Malone RP, Maislin G, Choudhury MS, Gifford C, Delaney MA. Risperidone treatment in children and adolescents with autism: short- and long-term safety and effectiveness. J Am Acad Child Adolesc Psychiatry. 2002;41(2):140-7.

21. Castro-Fornieles J, Parellada M, Soutullo CA, Baeza I, Gonzalez-Pinto A, Graell M, et al. Antipsychotic treatment in child and adolescent first-episode psychosis: a longitudinal naturalistic approach. J Child Adolesc Psychopharmacol. 2008;18(4):327-36. doi:10.1089/cap20070138.

22. Fleischhaker $\mathrm{C}$, Heiser $\mathrm{P}$, Hennighausen $\mathrm{K}$, HerpertzDahlmann B, Holtkamp K, Mehler-Wex C, et al. Weight gain in children and adolescents during 45 weeks treatment with clozapine, olanzapine and risperidone. J Neural Transm. 2008;115(11):1599-608. doi:10.1007/s00702-008-0105-9.

23. DelBello MP, Versavel M, Ice K, Keller D, Miceli J. Tolerability of oral ziprasidone in children and adolescents with bipolar mania, schizophrenia, or schizoaffective disorder. J Child Adolesc Psychopharmacol. 2008;18(5):491-9. doi:10.1089/cap2008008.

24. McConville B, Carrero L, Sweitzer D, Potter L, Chaney R, Foster K, et al. Long-term safety, tolerability, and clinical efficacy of quetiapine in adolescents: an open-label extension trial. J Child Adolesc Psychopharmacol. 2003;13(1):75-82.

25. Zuddas A, Di Martino A, Muglia P, Cianchetti C. Long-term risperidone for pervasive developmental disorder: efficacy, tolerability, and discontinuation. J Child Adolesc Psychopharmacol. 2000;10(2):79-90.

26. Findling RL, Johnson JL, McClellan J, Frazier JA, Vitiello B, Hamer RM, et al. Double-blind maintenance safety and effectiveness findings from the Treatment of Early-Onset Schizophrenia Spectrum (TEOSS) study. J Am Acad Child Adolesc Psychiatry. 2010;49(6):583-94. doi:10.1016/jjaac201003013. quiz 632

27. Findling RL, Pathak S, Earley WR, Liu S, DelBello M. Safety, tolerability, and efficacy of quetiapine in youth with schizophrenia or bipolar I disorder: a 26week, open-label, continuation study. J Child Adolesc Psychopharmacol. 2013;23(7):490-501.

28. Findling RL, Youngstrom EA, McNamara NK, Stansbrey RJ, Wynbrandt JL, Adegbite C, et al. Double-blind, randomized, placebo-controlled long-term maintenance study of aripiprazole in children with bipolar disorder. J Clin Psychiatry. 2012;73(1):57-63.

29. Ho J, Panagiotopoulos C, McCrindle B, Grisaru S, Pringsheim T. Management recommendations for metabolic complications associated with second- generation antipsychotic use in children and youth. Paediatr Child Health. 2011;16(9):575-80.

This article gives accurate and practical management recommendations for AE of SGA.

30. Pringsheim T, Panagiotopoulos C, Davidson J, Ho J. Evidence-based recommendations for monitoring safety of second-generation antipsychotics in children and youth. Paediatr Child Health. 2011;16(9):581-9

[This article gives update grade of recommendations for $\mathrm{AE}$ for each SGA specifically].

31. Menard L, Askenazy F. Assessment of incidence of adverse events in a naive pediatric population treated with antipsychotic drug. Neuropsychiatr Enf Adolesc. 2013;61:131-2.

32. Sikich L, Frazier JA, McClellan J, Findling RL, Vitiello B, Ritz L, et al. Double-blind comparison of first- and second-generation antipsychotics in early-onset schizophrenia and schizo-affective disorder: findings from the treatment of early-onset schizophrenia spectrum disorders (TEOSS) study. Am J Psychiatry. 2008;165(11):1420-31. doi:10.1176/ appiajp200808050756.

33. Bobo W, Cooper W, CM S, Olfson M, Graham D, Daugherty J, et al. Antipsychotics and the risk of type 2 diabetes mellitus in children and youth. JAMA. 2013;70(10):1067-75.

34. Charfi F, Cohen D, Houeto JL, Soubrie C, Mazet P. Tardive dystonia induced by atypical neuroleptics: a case report with olanzapine. J Child Adolesc Psychopharmacol. 2004;14(1):149-52.

35. Blair J, Taggart B, Martin A. Electrocardiographic safety profile and monitoring guidelines in pediatric psychopharmacology. J Neural Transm. 2004;111(7):791-815.

36. Brazman D, DelBello M, Alder C, Stanford KE, Strakowski SD. The efficacy and tolerability of quetiapine versus divalproex for the treatment of impulsivity and reactive aggression in adolescent with co-occurring bipolar disorder and disruptive behavior disorder(s). J Child Adolesc Psychopharmacol. 2006;16(6):665-70.

37. Sporn A, Bobb A, Gogtay N, et al. Hormonal correlates of clozapine-induced weight gain in psychotic children: an exploratory study. J Am Acad Child Adolesc Psychiatry. 2005;44:925-33.

38. Kumra S, Frazier J, Jacobsen L. Childhood-onset schizophrenia: a double-blind clozapine-haloperidol comparison. Arch Gen Psychiatry. 1996;53:1090-7.

39. Saito E, Correll CU, Gallelli K, et al. A prospective study of hyperprolactinemia in children and adolescents treated with atypical antipsychotic agents. J Child Adolesc Psychopharmacol. 2000;10(2):79-90. 2002;14:350-8.

40. Mozes T, Ebert T, Michal S, Spivak B, Weizman A. A. An open-label randomized comparison of olanzapine versus risperidone in the treatment of 
childhood-onset schizophrenia. J Child Adolesc Psychopharmacol. 2006;16(4):393403.

41. Ratzoni G, Gothelf D, Brand-Gothelf A, et al. Weight gain associated with olanzapine and risperidone in adolescent patients: a comparative prospective study. J Am Acad Child Adolesc Psychiatry. 2000;39(4):509-16. 2002;41:337-43.

42. Delbello M. Research on the effectiveness of risperidone in bipolar disorder in adolescents and children (REACH): a double-blind, randomized, placebocontrolled study of the efficacy and safety of risperidone for the treatment of acute mania in bipolar I disorder. http://downloadveritasmedicinecom/PDF/ CR003631_CSR.pdf. Accessed 07/28, 2010. 2005.

43. Haas M, Delbello MP, Pandina G, Kushner S, Van Hove I, Augustyns I, et al. Risperidone for the treatment of acute mania in children and adolescents with bipolar disorder: a randomized, double-blind, placebo-controlled study. Bipolar Disord. 2009;11(7):687-700. doi:10.1111/j1399-5618200900750x.

44. Findling RL, McNamara NK, Branicky LA, Schluchter MD, Lemon E, Blumer JL. A double-blind pilot study of risperidone in the treatment of conduct disorder. J Am Acad Child Adolesc Psychiatry. 2000;39(4):509-16.

45. Aman MG, De Smedt G, Derivan A, Lyons B, Findling RL. Double-blind, placebo-controlled study of risperidone for the treatment of disruptive behaviors in children with subaverage intelligence. Am J Psychiatry. 2002;159(8):1337-46.

46. Buitelaar JK, van der Gaag RJ, Cohen-Kettenis P, Melman CT. A randomized controlled trial of risperidone in the treatment of aggression in hospitalized adolescents with subaverage cognitive abilities. J Clin Psychiatry. 2001;62(4):239-48.

47. Snyder R, Turgay A, Aman M, Binder C, Fisman S, Carroll A. Effects of risperidone on conduct and disruptive behavior disorders in children with subaverage IQs. J Am Acad Child Adolesc Psychiatry. 2002;41(9):1026-36.

48. Jensen JB, Kumra S, Leitten W, Oberstar J, Anjum A, White T, et al. A comparative pilot study of secondgeneration antipsychotics in children and adolescents with schizophrenia-spectrum disorders. J Child Adolesc Psychopharmacol. 2008;18(4):317-26. doi:10.1089/cap20070123.

49. Biederman J, Mick E, Hammerness P, Harpold T, Aleardi M, Dougherty M, et al. Open-label, 8-week trial of olanzapine and risperidone for the treatment of bipolar disorder in preschool-age children. Biol Psychiatry. 2005;58(7):589-94.

50. Gaffney GR, Perry PJ, Lund BC, Bever-Stille KA, Arndt $\mathrm{S}$, Kuperman S. Risperidone versus clonidine in the treatment of children and adolescents with Tourette's syndrome. J Am Acad Child Adolesc Psychiatry. 2002;41(3):330-6.

51. Sikich L, Hamer RM, Bashford RA, Sheitman BB, Lieberman JA. A pilot study of risperidone, olanzapine, and haloperidol in psychotic youth: a double-blind, randomized, 8-week trial. Neuropsychopharmacology. 2004;29(1):133-45.

52. Haas M, Unis AS, Armenteros J, Copenhaver MD, Quiroz JA, Kushner SF. A 6-week, randomized, double-blind, placebo-controlled study of the efficacy and safety of risperidone in adolescents with schizophrenia. J Child Adolesc Psychopharmacol. 2009;19(6):611-21. doi:10.1089/cap20080144.

53. Pavuluri MN, Henry DB, Findling RL, Parnes S, Carbray JA, Mohammed T, et al. Double-blind randomized trial of risperidone versus divalproex in pediatric bipolar disorder. Bipolar Disord. 2010;12(6):593-605. doi:10.1111/j1399-5618201000850x.

54. Haas M, Eerdekens M, Kushner S, Singer J, Augustyns I, Quiroz J, et al. Efficacy, safety and tolerability of two dosing regimens in adolescent schizophrenia: doubleblind study. Br J Psychiatry. 2009;194(2):158-64. doi:10.1192/bjpbp107046177.

55. Tohen M, Kryzhanovskaya L, Carlson G, Delbello M, Wozniak J, Kowatch R, et al. Olanzapine versus placebo in the treatment of adolescents with bipolar mania. Am J Psychiatry. 2007;164(10):1547-56.

56. Kryzhanovskaya L, Schulz SC, McDougle C, Frazier J, Dittmann R, Robertson-Plouch $\mathrm{C}$, et al. Olanzapine versus placebo in adolescents with schizophrenia: a 6-week, randomized, double-blind, placebo-controlled trial. J Am Acad Child Adolesc Psychiatry. 2009;48(1):60-70. doi:10.1097/ CHIOb013e3181900404.

57. Marcus RN, Owen R, Kamen L, Manos G, McQuade $\mathrm{RD}$, Carson WH, et al. A placebo-controlled, fixeddose study of aripiprazole in children and adolescents with irritability associated with autistic disorder. J Am Acad Child Adolesc Psychiatry. 2009;48(11):1110-9. doi:10.1097/ CHIOb013e3181b76658.

58. Owen R, Sikich L, Marcus RN, Corey-Lisle P, Manos G, McQuade RD, et al. Aripiprazole in the treatment of irritability in children and adolescents with autistic disorder. Pediatrics. 2009;124(6):1533-40. doi:10.1542/peds2008-3782.

59. Croonenberghs J, Fegert JM, Findling RL, De Smedt G, Van Dongen S. Risperidone in children with disruptive behavior disorders and subaverage intelligence: a 1year, open-label study of 504 patients. J Am Acad Child Adolesc Psychiatry. 2005;44(1):64-72.

60. Sallee FR, Kurlan R, Goetz CG, Singer H, Scahill L, Law $\mathrm{G}$, et al. Ziprasidone treatment of children and adolescents with Tourette's syndrome: a pilot study. J Am Acad Child Adolesc Psychiatry. 2000;39(3):292-9.

61. Findling RL, Robb A, Nyilas M, Forbes RA, Jin N, Ivanova $S$, et al. A multiple-center, randomized, double-blind, placebo-controlled study of oral aripiprazole for treatment of adolescents with schizophrenia. Am J Psychiatry. 2008;165(11):143241. doi:10.1176/appiajp200807061035. 
62. DelBello MP, Chang K, Welge JA, Adler CM, Rana M, Howe $\mathrm{M}$, et al. A double-blind, placebo-controlled pilot study of quetiapine for depressed adolescents with bipolar disorder. Bipolar Disord.

2009;11(5):483-93. doi:10.1111/j1399$5618200900728 \mathrm{x}$.

63. DelBello MP, Kowatch RA, Adler CM, Stanford KE, Welge JA, Barzman DH, et al. A double-blind randomized pilot study comparing quetiapine and divalproex for adolescent mania. J Am Acad Child Adolesc Psychiatry. 2006;45(3):305-13.

64. Correll CU. From receptor pharmacology to improved outcomes: individualising the selection, dosing, and switching of antipsychotics. Eur Psychiatry. 2010;25:S12-21.

This article gives relevant advice and practical advice to switch from one SGA to another.

65. Constant E. Clinical stakes when switching from one antipsychotic to another. Encéphale. 2013. doi:10.1016/jencep201310001.

66. Kumra S, Kranzler H, Gerbino-Rosen G, Kester HM, DeThomas C, Cullen K, et al. Clozapine versus "highdose" olanzapine in refractory early-onset schizophrenia: an open-label extension study. J Child Adolesc Psychopharmacol. 2008;18(4):307-16. doi:10.1089/cap20070089.

67. Findling RL, McKenna K, Earley WR, Stankowski J, Pathak S. Efficacy and safety of quetiapine in adolescents with schizophrenia investigated in a 6-week, double-blind, placebo-controlled trial. J Child Adolesc Psychopharmacol. 2012;22(5):327-42. doi:10.1089/cap.2011.0092.

68. Pathak S, Findling RL, Earley WR, Acevedo LD, Stankowski J, Delbello MP. Efficacy and safety of quetiapine in children and adolescents with mania associated with bipolar I disorder: a 3-week, doubleblind, placebo-controlled trial. J Clin Psychiatry. 2013;74(1):e100-9. doi:10.4088/JCP.11m07424.

69. Bonnot O, Inaoui R, Linares CL, Cohen D. Surveillance of metabolic syndrome, hyperprolactinemia and cardiac side effects in children and adolescent treated with antipsychotic. Actuality and recommendations. J Neuropsychiatr L'enfant. 2009;09.004.

70. Findling R, Cavus I, Pappadopulos E, Vanderburg D, Schwartz J, Gundapaneni B, et al. Ziprasidone in adolescents with schizophrenia: results from a pla- cebo-controlled efficacy and long-term open-extension study. J Child Adolesc Psychopharmacol. 2013;23(8):531-44.

71. Blair J, Scahill L, State M, Martin A. Electrocardiographic changes in children and adolescents treated with ziprasidone: a prospective study. J Am Acad Child Adolesc Psychiatry. 2005;44(1):73-9.

72. Findling R, Cavus I, Pappadopulos E, Vanderburg D, Schwartz J, Gundapaneni B, et al. Efficacy, long term safety, and tolerability of ziprasidone in children and adolescent with bipolar disorder. J Child Adolesc Psychopharmacol. 2013;23(8):545-57.

73. Alfaro CL, Wudarsky M, Nicolson R, Gochman P, Sporn A, Lenane $\mathrm{M}$, et al. Correlation of antipsychotic and prolactin concentrations in children and adolescents acutely treated with haloperidol, clozapine, or olanzapine. J Child Adolesc Psychopharmacol. 2002;12(2):83-91.

74. Kleinberg DL, Davis JM, de Coster R, Van Baelen B, Brecher M. Prolactin levels and adverse events in patients treated with risperidone. J Clin Psychopharmacol. 1999;19(1):57-61.

75. Volavka J, Czobor P, Citrome L, Van Dorn RA. Effectiveness of antipsychotic drugs against hostility in patients with schizophrenia in the Clinical Antipsychotic Trials of Intervention Effectiveness (CATIE) study. CNS Spectr. 2013;28:1-8.

76. Jones PB, Barnes TR, Davies L, Dunn G, Lloyd H, Hayhurst KP, et al. Randomized controlled trial of the effect on Quality of Life of second- vs first-generation antipsychotic drugs in schizophrenia: Cost Utility of the Latest Antipsychotic Drugs in Schizophrenia Study (CUtLASS 1). Arch Gen Psychiatry. 2006;63(10):1079-87.

77. Kahn RS, Fleischhacker WW, Boter H, Davidson M, Vergouwe Y, Keet IP, et al. Effectiveness of antipsychotic drugs in first-episode schizophrenia and schizophreniform disorder: an open randomised clinical trial. Lancet. 2008;371(9618):1085-97. doi:10.1016/S0140-6736(08)60486-9.

78. McEvoy JP, Lieberman JA, Perkins DO, Hamer RM, $\mathrm{Gu} \mathrm{H}$, Lazarus A, et al. Efficacy and tolerability of olanzapine, quetiapine, and risperidone in the treatment of early psychosis: a randomized, doubleblind 52-week comparison. Am J Psychiatry. 2007;164(7):1050-60. 